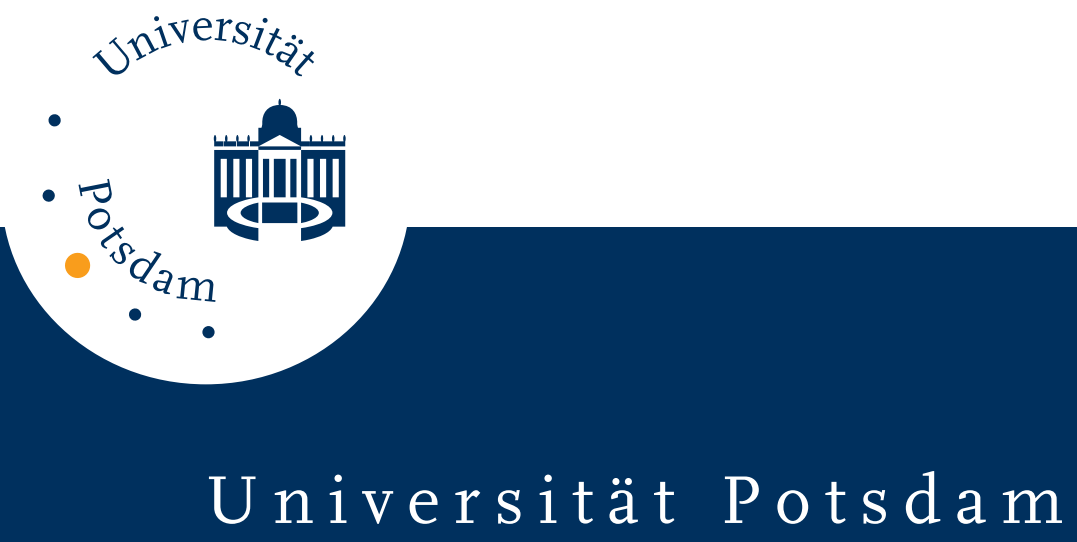

Ulrich Schiefele

\title{
Topic interest and levels of text comprehension
}

first published in:

The role of interest in learning and development / K. A. Renninger, S. Hidi \& A. Krapp (Eds.). - Hillsdale, NJ : Erlbaum, 1992

Postprint published at the Institutional Repository of Potsdam University:

In: Postprints der Universität Potsdam

Humanwissenschaftliche Reihe ; 67

http://opus.kobv.de/ubp/volltexte/2009/3369/

http://nbn-resolving.de/urn:nbn:de:kobv:517-opus-33696

Postprints der Universität Potsdam

Humanwissenschaftliche Reihe ; 67 


\title{
7 Topic Interest and Levels of Text Comprehension
}

\author{
Ulrich Schiefele \\ Universität der Bundeswehr - Munich
}

The relation between interest and both comprehension and learning is not a new topic, although it has long been absent from educational research (Krapp, 1989; Renninger \& Wozniak, 1985; Schiefele \& Winteler, 1988). Herbart $(1806,1841)$, one of the early pioneers of modern psychology, worked intensively in this area. He regarded the development of unspecialized, multi-faceted interest as one of the primary goals of education. In addition, Herbart assumed a very close relation between interest and learning. In his opinion, it is primarily interest that allows for correct and complete recognition of an object, leads to meaningful learning, promotes long-term storage of knowledge, and provides motivation for further learning. Herbart's work was not taken up by any immediate successor, and his theory lay dormant until the turn of the century, when leading psychologists and educators again took it up and developed it (e.g., Cattell, 1936; Dewey, 1913; Kerschensteiner, 1922; Thorndike, 1935a, 1935b).

Dewey (1913) continues to be one of the most important and influential theorizers about interest and motivation. Dewey postulated three basic characteristics of interest: (a) it is an active, "propulsive" state, (b) it is based on real objects, and (c) it has high personal meaning. In his opinion, the results of interest-based learning differ qualitatively from the results of learning that is based only on effort. Effort-based learning is mechanical and results in "trained" knowledge and habits lacking any mental purpose or worth. Interest, on the other hand, is characterized by a 
sense of pleasure arising out of and accompanying the activity. This sense of pleasure results from the satisfaction of psychological needs.

Dewey dismisses educational efforts toward learning that take place without regard to the material to be learned. He maintains, however, that being interested in a topic does not imply that no effort is required to learn about it. Effort is, in fact, regarded as an important part of interest-based activity. Dewey, therefore, distinguishes interest-based learning from learning that neglects a student's interests in that interest-based learning requires no coercion. According to Dewey, external attempts to "make something interesting" lead to only temporary effort and do not result in identification with the material.

Both Dewey and Herbart hypothesized that the results of interest-based learning differ qualitatively from the results achieved by mechanical or instrumentally motivated learning. Unfortunately, empirical research following their work has been limited to a few scattered studies (e.g., Bernstein, 1955; Witty \& Kopel, 1936). During the last two decades, however, a series of studies focusing on the relation between interest and text comprehension has been conducted.

\section{PRIOR RESEARCH ON THE INFLUENCE OF INTEREST ON TEXT COMPREHENSION}

Although little noticed by the mainstream of text-related research, an increasing number of studies is concerned with the significance of interest for text comprehension. Initial work in this area was conducted by Asher (summarized in Asher, 1980). In recent years, more and more studies have been devoted to this topic (see the overviews by Hidi \& Baird, 1986; and Schiefele, 1988).

The research has focused on two different conceptions of interest: individual or personal interest in a topic, and situational interest (Hidi, 1990). Individual interest is conceived of as a relatively enduring preference for certain topics, subject areas, or activities (e.g., Prenzel, 1988; Renninger, 1990; Schiefele, 1990a, in press b), whereas situational interest is defined as an emotional state aroused by situational stimuli (e.g., Anderson, Shirey, Wilson, \& Fielding, 1987; Hidi, 1990). Research supports the general conclusion that both individual and situational interest have a positive influence on text comprehension (e.g., Anderson, Mason, \& Shirey, 1984; Asher, 1980; Baldwin, Peleg-Bruckner, \& McClintock, 1985; Belloni \& Jongsma, 1978; Bernstein, 1955; Entin \& Klare, 1985; 
Hidi \& Baird, 1988; Osako \& Anders, 1983; Renninger, 1988; Stevens, 1979). This phenomenon is relatively independent of the age of subjects, the type of text (narrative vs. expository), the mode of text presentation (written vs. oral), and the kind of comprehension test (free and cued recall, "cloze" procedure, multiple-choice, and open-ended questions).

In spite of these positive results, the studies conducted to date are inadequate in a number of ways. The most obvious problem is the lack of an elaborated definition or theory of interest. The everyday meaning of the term interest is assumed to adequately delineate the concept. As a result, the measurement of interest often involves only a single rating scale where subjects are asked to indicate whether they find a topic or sentence to be extremely, quite, somewhat, hardly, or not at all interesting.

Another problem is that no attempt has been made to identify the features of interest-based text processing and to compare this mode with other modes of processing (e.g., processing based on extrinsic motivation). Only Anderson (1982) and Shirey and Reynolds (1988) have conducted studies that offer an explanation for the interest effect. They hypothesized that more attention is invested in interesting sentences. Their results, however, did not indicate that greater retention of interesting sentences is based on (consciously) increased attention.

A further crucial problem is the inadequate consideration of relevant control variables that affect interest and comprehension. Most studies have involved school-age subjects and have controlled for reading ability and text readability (e.g., Anderson et al. 1984; Baldwin et al., 1985; Cecil, 1984; Entin \& Klare, 1985; Klein, 1979; Stevens, 1979). However, only a few studies have controlled for prior knowledge and intelligence. Although the influences of reading ability and readability on text comprehension have been unanimously shown to be independent of interest, these results cannot be transferred to prior knowledge or intelligence. Studies involving prior knowledge have achieved inconsistent results (e.g., Baldwin et al., 1985; Entin \& Klare, 1985; Hare \& Devine, 1983; Osako \& Anders, 1983). Some studies have confirmed that interest affects comprehension independently of prior knowledge; others have suggested that knowledge mediates the effect of interest.

Finally, given the widespread preference for simple indicators of comprehension, studies of interest and its effect on reading comprehension do not allow any conclusions about qualitatively different levels of processing. Usually, these indicators are based on recognition tests (especially in a multiple-choice format) and, to a lesser extent, on 
free-recall tests and open-ended questions. Unfortunately, the use of these methods has been restricted to the measurement of purely quantitative aspects of text comprehension (e.g., number of words reproduced). In contrast, Bernstein (1955) proposed some time ago a number of qualitative comprehension indicators that could conceivably be influenced by interest, such as "word knowledge," "recognition of the main idea of a text passage," and "making conclusions about the text content."

In this chapter, I examine more thoroughly three of the problems just mentioned and offer possible solutions. Specifically, a definition of individual interest is proposed, the possible relation between interest and levels of processing or comprehension is explored, and the problem of mediating variables is discussed.

\section{THEORETICAL CONSIDERATIONS}

\section{Conceptualization of Individual Interest}

Based on older theories of interest (see overview by Schiefele \& Winteler, 1988) and with reference to the interest concept of $\mathrm{H}$. Schiefele and his colleagues (Prenzel, 1988; Prenzel, Krapp, \& H. Schiefele, 1986; H. Schiefele, Hausser, \& Schneider, 1979; H. Schiefele, Krapp, Prenzel, Heiland, \& Kasten, 1983), individual interest can be interpreted as the relatively long-term orientation of an individual toward a type of object, an activity, or an area of knowledge (see also the chapter by Renninger, this volume, for a discussion of individual interest as a psychological state).

One must distinguish between two components of interest: a feelingrelated and a value-related component. These components can be described more precisely using concepts from the field of motivational psychology. The taxonomy of motivational characteristics developed by Pekrun (1988) is central to such an undertaking. Using this taxonomy, it is possible to differentiate between cognitive representations of expectations, goals, and valences. Referring to this distinction, I propose to reinterpret interest as a domain-specific or topic-specific motivational characteristic of personality, which is composed of feeling-related and value-related valences. The term feeling-related valences is used when a topic or object is associated with feelings that precede, accompany, or follow activity involving the topic or object of interest. Typical of interest would be feelings of enjoyment or involvement. If personal significance is ascribed to a topic, one speaks of a "cognitive" or a value-related valence. On the 
basis of this distinction, it is possible to define topic interest as being composed of both feeling-related (relating a topic to particular feelings) and value-related valences (attributing personal significance to a topic).

A third important feature of interest is its intrinsic character, also termed self-intentionality by $\mathrm{H}$. Schiefele et al. (1983). In the context of text learning, this means that the learner should be involved in a topic for its own sake and not for any external reason (e.g., passing an exam). The feeling-related and value-related valences can, therefore, be described more precisely as intrinsic feeling-related and value-related valences. To measure interest then, the topic valences involved must be directly related to the topic (or to reading a text on a certain topic) and not, for example, to other topics or external events. A summary of the proposed definition of individual interest is shown in Table 7.1.

Table 7.1

Definition of Individual Interest

Individual Interest (Topic Interest)

Feeling-Related Component Value-Related Component

Association of a topic or topic-related activity with positive feelings, especially enjoyment and involvement (feeling-related intrinsic Attributing of personal significance to a topic (value-related intrinsic valences of a topic)

Our discussion of the concept of "topic interest" has left aside a clarification of the term topic. ${ }^{1}$ However, Hidi and McLaren (1988) have recently defined a topic as a "coherent knowledge domain of subject

1 Of course, topics are not the only entities people are interested in. Krapp and Fink (1987), for example, discem three different categories of interest objects: activities, material objects, and topics. 
matter" (p. 4). They cite "space travel" and "wildlife" as typical examples of topics that are of interest to school-aged children. Furthermore, Hidi and McLaren distinguish topics from "themes." Themes cut across different topics and are, therefore, more abstract generalizations of specific topic contents. For example, the themes "survival" and "future" can both be regarded as generalizations of the aforementioned topics "space travel" and "wildlife." Themes, then, can cover rather heterogeneous knowledge domains.

So far, we have only dealt with interest as a latent characteristic. In order to become effective, however, latent interest has to be activated by either internal or external stimuli. Therefore, it is necessary to distinguish a second form of individual interest, namely actualized individual interest.

Actualized interest is best described as a content-specific intrinsic motivational orientation. Basically, this means that a person in a state of being interested in a certain topic wants to learn about (or become involved with) that topic for its own sake. In other words, the interested person adopts a task- or learning-orientation (as opposed to an ego- or performance-orientation) towards a specific topic (cf. Nicholls, 1984; Nolan, 1988). It should be noted that the concepts of task- and learningorientation are usually defined as general orientations towards learning material in school. In contrast, the interest concept is based on the idea that people develop specific relations with different subject areas.

Interest and the Concept of Motivational Orientation

The concept of different motivational orientations has recently been stressed by several authors (cf. Lepper, 1988). Motivational orientation generally describes an individual's habitual orientation toward certain goals. A good example of this is the distinction made by Nicholls (1984) between task-oriented and ego-oriented motivation (see also Nolen, 1988; Ryan, 1982). Other similar distinctions have been suggested by Dweck (1986; Dweck \& Leggett, 1988) and Harter (1981). According to Lepper (1988), these efforts point to two central components of a motivational orientation conducive to learning: (a) the willingness to engage in an activity for its own sake (intrinsic component), and (b) the belief that one is the initiator of a learning activity and is solely responsible for its results. This also corresponds to Deci and Ryan's (1985) theory of intrinsic motivation, whereby intrinsically motivated behavior is based upon psychological needs for self-determination and competence. 
It seems reasonable to assume a great deal of similarity between an intrinsic or task-oriented motivational orientation and the concept of interest. However, a major difference between these conceptions concerns their domain specificity. Motivational orientations are usually defined as general concepts. They are assumed to affect, for example, a student's learning behavior across different subjects. In contrast, interest is a domain-specific characteristic. It enables us to acknowledge the fact that some students are, for example, motivated to learn mathematics, whereas they really dislike learning a foreign language or chemistry.

General motivational orientations and specific interests are not, however, mutually exclusive. Presumably, a person has both more general orientations towards academic tasks and content-specific interests. It is believed that both general orientations and individual interests determine the strength and nature of the specific motivational orientation a student adopts in a specific situation involving a specific learning content. However, interest is expected to be more predictive of specific motivational orientations and, therefore, of outcomes of specific learning processes.

\section{The Effect of Interest on Different Levels of Comprehension}

To date, attempts to answer the question of whether interest has different effects at different levels of comprehension have yielded no clear results. Bernstein (1955), who conducted one of the first studies on the effect of interest on text comprehension, identified a number of components of comprehension, ranging from "word knowledge" to "recognition of author's intent." Bernstein's results, however, were not broken down into individual components, and it is impossible to know how many of these components were accounted for in her test of comprehension. A more informative study was carried out by Fransson (1977), who showed that students who were more interested in a topic exhibited deeper processing of a related text. Using free recall and extensive interviews, Fransson found that high-interest subjects made more connections not only between different parts of the text, but also between what was read and prior knowledge or personal experience. The subjects were also found to do more independent thinking about the text content.

In another study that centered around text comprehension, Benware and Deci (1984) demonstrated that intrinsically motivated students exhibit markedly greater conceptual comprehension of text content than extrinsically motivated students. No differences were obtained, however, in the number of details subjects were able to reproduce (rote learning). 
Different types of questions were used to measure comprehension, including definitions, multiple-choice questions, and explanations. Using a different set of experimental conditions and procedures, Grolnick and Ryan (1987) came to essentially the same results as Benware and Deci.

Other studies have also attempted to investigate the effect of interest on comprehension by including various components of comprehension. Groff (1962) explored three levels of comprehension: recognition of text organization, inferences, and conclusions. Johnson and Jacobson (1968) distinguished between literal and interpretive comprehension. Similarly, Stevens (1979) differentiated between literal and inferential comprehension. Unfortunately, these studies only report overall results (which reveal significant interest effects), without separating the effects of interest on different components of comprehension. Moreover, none of these studies was based upon any particular model of text processing or representation. The criteria for judging depth of comprehension were deduced more or less intuitively.

Findings from two recent studies (Schiefele \& Krapp, 1988; Schiefele, Winteler, \& Krapp, 1988) revealed that university students who were highly interested in their majors did not produce any more associations with subject-related terms (e.g., "learning," "instruction," "socialization") than did less interested students. Rather, the associations of the highinterest group were more adequate in a technical sense than were those of the low-interest group. In addition, important differences in the cognitive structure of the stimulus concepts were found.

In summary, it appears that interest is of less importance when superficial knowledge, explicitly contained in a text, is required, and of greater importance when deeper comprehension of text content is required. It is presumed that an explanation of this difference can be determined only by examining mediating processes.

Mediating Processes Involved in the Effect of Interest on Text Comprehension

It would seem that the effect of interest on comprehension can only be explained by studying the process of interest-based learning, yet only a small number of studies concerning this issue has been conducted (Lepper, 1988; Schiefele, 1987). Such studies have usually been limited to the study of single factors, such as the role of attention while reading, and there has been a lack of more comprehensive theoretical consideration. 
In this chapter, a model is presented that depicts the influence of topic interest on text comprehension as well as the processes that presumably mediate that influence (see Fig. 7.1). It is assumed that the stimulation of topic interest leads to actualized interest (i.e., a topic-specific intrinsic motivational orientation), which, in turn, exerts an influence on cognitive (e.g., elaborative processes) and emotional variables (e.g., level of activation) of the learning process. It is believed that emotional and cognitive variables interact with one another. On the one hand, emotional states presumably influence, for example, the willingness to use learning strategies, to invest effort, and to draw inferences. On the other hand, the level of cognitive involvement with the task at hand may contribute to the quality of emotional experience.

The outcome of the learning process is thought to be the result of cognitive and emotional processes. It is assumed that cognitive processes are generally more important than affective ones, at least as far as the immediate learning result is concerned. However, it is possible that this hypothesis must be modified according to the nature of the desired learning result (e.g., fact vs. conceptual understanding).

As is shown in Fig. 7.1, only indirect effects of topic interest on text comprehension are hypothesized. Thus, the effect of interest depends on its impact on the quality of the mediating emotional and cognitive processes. Because it is not possible in this chapter to focus on all of the relations between concepts shown in Fig. 7.1, only mediators of the influence of topic interest on text comprehension will be dealt with here. Specifically, previous research findings involving these mediators are discussed.

The work of Entwistle and Ramsden (1983, see also Entwistle, 1988) leads to the conclusion that intrinsic motivation to learn corresponds to a "deep approach" orientation to learning, which results in deeper comprehension. In summary, they report that intrinsically motivated students make greater attempts than other students to relate new information to prior knowledge, similar topics, concrete examples, or personal experience. The learning of extrinsically motivated students, on the other hand, is more superficial and mechanical, often involving the repeated reading of a text or outright memorization of certain passages.

In a recent study, Nolen (1988) confirmed and added to the results of Entwistle and Ramsden. She gave a scientific text to a group of school children and found that the children who exhibited a task-orientated motivation (i.e., motivation directed toward the comprehension of the 


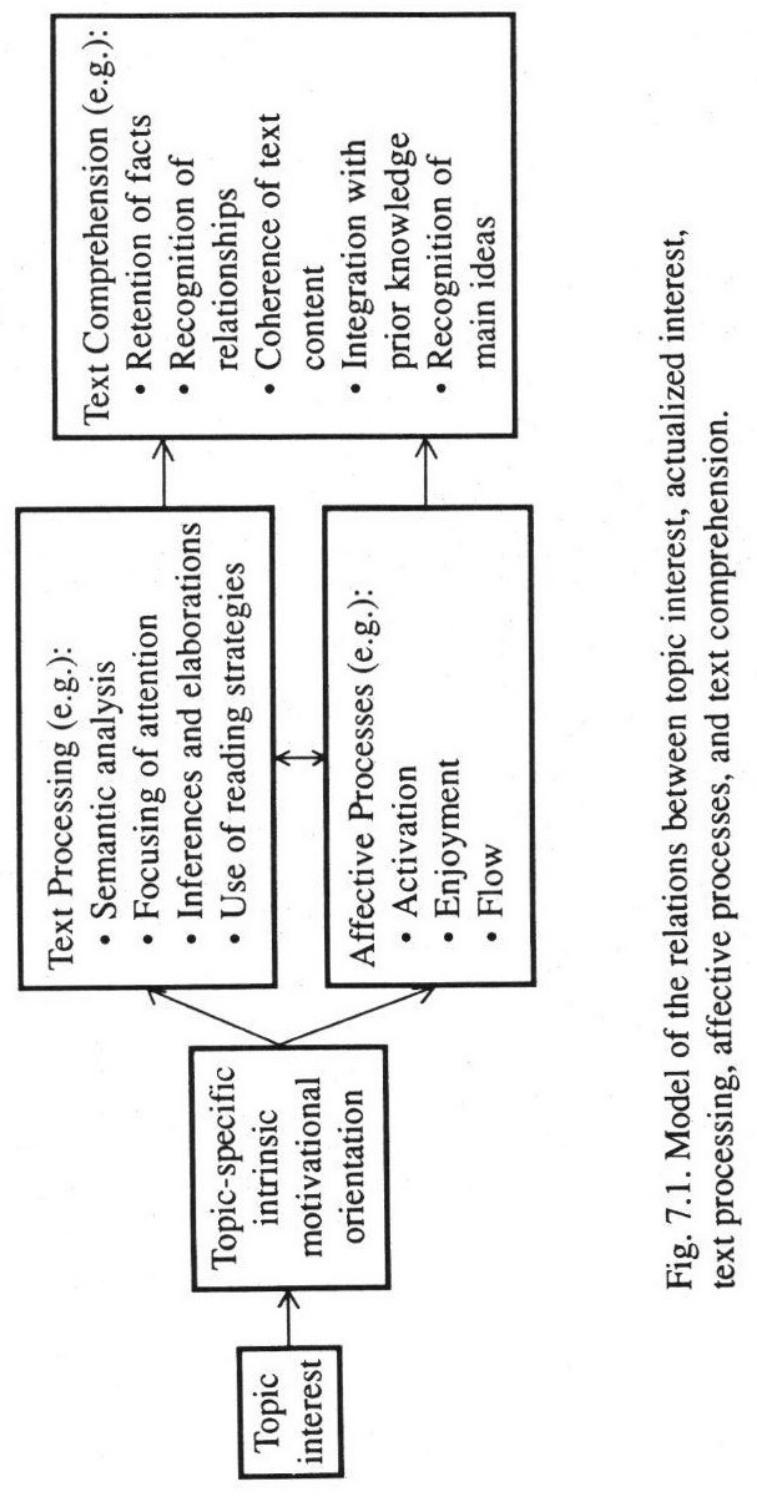


text), used learning strategies that permitted both deeper comprehension and superficial processing. Children exhibiting an ego-oriented motivation (i.e., with the primary goal of getting better grades than their peers) used only those learning strategies that allowed them to read quickly and remember the text. Self-estimation of ability to comprehend scientific texts and knowledge of learning strategies proved to be relatively unimportant in the selection of learning strategies. Unfortunately, the analysis of retention revealed little, because the texts used were obviously too difficult for the subjects and the variance in their scores was too small. Thus, no significant correlations between motivational orientation and retention were found.

Anderson (1982; see also Anderson et al., 1987) and Shirey and Reynolds (1988) investigated whether subjects invested more attention in more interesting sentences than in less interesting sentences. Two different methods for assessing attention were used: sentence reading time and reaction time to a secondary task. Slow reading and reaction times are indicative of high levels of attention. Anderson's study, which involved fourth-grade schoolchildren, showed a positive relation between interest and attention, whereas the study by Shirey and Reynolds, which involved university students, yielded a negative relation between the same factors. In both cases, interest had a significant influence on learning, but the level of attention had no corresponding effect. According to Shirey and Reynolds, these results suggest that especially adult (or skilled) readers pay less attention to interesting sentences because they know that it is easy to remember interesting material. Hidi (1990), however, has challenged that interpretation. Her work suggests that interest facilitates spontaneous, or involuntary, attention rather than intentional, or voluntary, attention. As a consequence, she maintains that interest could be associated with faster reading and reaction times, because spontaneous attention is less effortful and, thus, allows for more efficient processing of text.

One common feature of all the studies reviewed so far is that only cognitive variables (attention and learning strategies) were considered as mediating processes. As our model in Fig. 7.1 indicates, affective variables are also influential in the comprehension process. Although the assumed influence of activation on cognitive processes has been found in numerous studies (cf. Eysenck, 1982; Guttmann, 1982; Thayer \& Cox, 1968), less is known about the mediating role of other affective states. Some studies suggest, however, that emotions are also of considerable significance (Bloom, 1985; Bower \& Cohen, 1982; Csikszentmihalyi, 1988; Isen, Daubman, \& Gorgoglione, 1987; Mandl \& Huber, 1983). 
Csikszentmihalyi $(1975,1988,1990)$, in particular, has claimed that individuals can reach the optimum level of their cognitive capacities only when experiencing a state he has called "flow." He found that people who are strongly interested or intrinsically motivated to engage in an activity (e.g., playing chess) sometimes experience a state of optimal experience or flow. When being in flow, time seems to pass quickly, attention is sharply focused, and the individual becomes "lost" in the activity. Although the person so engaged is unconscious of self, there is, nevertheless, a feeling of control over the current activity. Csikszentmihalyi (1975; see also Csikszentmihalyi \& Csikszentmihalyi, 1988) showed that the experience of flow is a powerful explanation of why people engage in certain activities without any extrinsic reinforcement.

Flow can occur to different degrees during any activity. A necessary condition is that the person sees both the level of task difficulty (or challenge) and his/her ability in the task as higher than average. It seems reasonable to conclude that readers displaying high levels of topic interest are prone to experience flow during the reading process. In fact, flow can be regarded as a state of "deep interest" (Rathunde, 1989). It remains unclear, however, whether flow is just an epiphenomenon of topic interest or whether flow actually mediates the effect of interest on comprehension processes or outcomes. To date, no conclusive empirical tests to resolve that problem have been conducted. Larson (1988) showed that essays of schoolchildren who experienced a flow-like state while writing were more exciting, better structured, and more creative than those of other students. This result, however, yields at best only indirect information about the relation between flow and text processing.

The flow model relates experiential states to both interests and cognitive or learning processes. Flow is a holistic, multi-componential state of experience that typically involves high levels of activation, enjoyment, and concentration (e.g., Csikszentmihalyi \& Larson, 1987; Csikszentmihalyi \& LeFevre, 1989). Thus, it would seem desirable to investigate whether flow or its components are capable of mediating the effect of interest on text comprehension.

\section{EMPIRICAL EVIDENCE}

\section{Goals and Procedures}

In the following, the results of two studies are reported that were intended to answer to the issues raised by previous studies. Specifically, our studies 
were designed to (a) test the impact of topic interest on various levels of comprehension, (b) examine whether interest affects comprehension independently of prior knowledge and intelligence, and (c) explore the mediating effects of selected process variables that could serve to explain the interest effect.

Both studies used the same experimental design ${ }^{2}$ (see Table 7.2). First, subjects' prior knowledge, verbal and general intelligence, and short-term memory capacity were measured. This was followed by an assessment of subjects' topical interest in the experimental text. On the basis of the interest measure, subjects were divided into high- and low-interest groups and asked to read a text. In the final phase of the study, comprehension of the text and indicators of text processing were assessed.

Table 7.2

Design of Experimental Studies

Pre-Experimental Phase

Measurement of Control Variables: Prior Knowledge, Intelligence, Short-Term Memory

Experimental Phase

Measurement of topic interest

Reading phase

Topic of text in Study I: Psychology of emotion

Topic of text in Study II: Psychology of communication

Measurement of process variables

Cognitive variables: Elaboration, Underlining, Note-taking

Motivational variables: Activation, Flow

Measurement of comprehension

Study I: Open-ended questions

Study II: Recognition test

2 A more detailed account of methodological aspects of the studies is to be found in Schiefele (1990a, 1990b, in press a). 
A total of 96 male first-semester students participated in the investigations. There were 53 computer science majors in Study I and 43 social science majors in Study II. Two subjects were excluded from Study II because of outlying data. Data collection took place during regular class time; average class sizes were 25 people. A different text was used for each study.

Procedures for the two studies were the same: 2 to 4 weeks after the pretests, subjects were given written instructions asking them to evaluate sample texts from psychology textbooks. No mention was made that there would be a comprehension test later. Subjects were then told the topic and presented with a short summary of the text. Following this, they were asked to respond to the interest scale.

The next 15 minutes were allotted for reading the complete text. Subjects were allowed to make notes in the page margins and to underline portions of the text. Immediately following the reading period, the process variables of activation, flow experience, and elaborations were measured. Finally, a comprehension test was administered.

In the selection of the experimental texts, two criteria were considered. First, the subjects should have only limited prior knowledge of the text's topic. Second, interest in the topic should display large variance. Accordingly, the topic "Emotion" was chosen for Study I, and the topic "Communication" for Study II. The texts were about five pages long and consisted of three (Emotion) and four (Communication) sections.

In determining topical interest we attempted to measure intrinsic feeling-related and value-related valences. The feeling-related valences were operationalized as the expectation of experiencing certain feelings while reading the experimental text. Subjects were asked to use the following adjectives in estimating their expected feelings: ("While reading the text on '...', I expect to feel") "bored," "stimulated," "interested," "indifferent," "involved," and "engaged." When estimating value-related feelings, subjects were asked to use the terms "meaningful," "unimportant," "useful," and "worthless" to describe the value of the text's topic to them personally. Both scales relating to topic interest as well as all other scales consisted of four response categories: "not at all," "somewhat," "quite," and "completely." Individual values of topic interest were computed by adding the scores for the two components.

A more detailed description of the comprehension tests, the control variables, and the measurement of mediating variables follows. 


\section{Interest and Levels of Comprehension}

Measurement of Text Comprehension in Study I. Following the work of Ballstaedt and Mandl (1987), the test of comprehension included three types of questions: 6 simple questions, 3 complex questions, and 3 deeper comprehension questions. The simple questions involved recall of concrete details (e.g., individual facts, definitions) stated explicitly in the text (e.g., "Which descriptive dimensions does Wundt consider characteristic for all emotions?"). The complex questions also related to knowledge explicitly contained in the text, but pertained to groupings of facts or relations between facts rather than to single facts (e.g., "What disadvantages are involved in the measuring of physiological changes in the study of emotions?"). The questions of deeper compre-hension required the subjects to recombine or to compare various aspects of the text and to apply the information contained in the text to a novel situation (e.g., "Two students report feeling 'very anxious' before taking an exam. What are the pros and cons of assuming that the two students are experiencing the same emotion?").

Because not all questions were assigned the same number of points, individual scores were converted into $z$-values. In order to arrive at only positive values, all $z$-values were increased by 1 . Evaluation of the comprehension test was conducted by two independent trained raters, using an answer key containing model answers. In $10.3 \%$ of all evaluated answers, the raters arrived at different results.

Results of Study I. The results of the analysis of the comprehension test are presented in Table 7.3. A main effect for interest was obtained (ANOVA, $p<.005$ ), due in large part to the difference between the two subject groups in answering questions of deeper comprehension (planned comparison, $p<.001)$. The differences in the cases of the simple $(n s)$ and complex questions $(p<.05)$ are distinctly smaller. The overall pattern of results confirms the hypothesis that interest exerts greater influence at deeper levels of comprehension.

In order to further examine this conclusion, the results of the comprehension test were compared with a more objective measure, namely the length of answers given by the subjects. Analysis of the length of answers shows that, for all three question types, subjects in the high-interest group gave longer answers ( $M=21.08$ vs. $M=18.62$ words per question). Whereas this trend lies in the theoretically postulated direction, it is not significant. Thus, the significant differences in comprehension for complex questions and for questions of deeper comprehension, as indicated 
Table 7.3

Text Comprehension (z-Scores) as a Function of Topic Interest (Study I)

\begin{tabular}{lrrrr}
\hline Topic Interest & \multicolumn{1}{c}{$S Q$} & \multicolumn{1}{c}{$C Q$} & DCQ & Total \\
\hline Low $(n=27)$ & .88 & .83 & .74 & .83 \\
High $(n=26)$ & 1.13 & 1.18 & 1.27 & 1.17 \\
\hline
\end{tabular}

Note: SQ: Simple questions; CQ: Complex questions; DCQ: Deeper comprehension questions.

before, cannot simply be explained by the length of answers given. Instead, high- and low-interest subjects must differ in terms of the quality of their answers.

Study I shows that topic interest is a very influential motivational condition of text comprehension. The effect of interest on text comprehension is especially noticeable in the case of questions of deeper comprehension. Whether high-interest subjects actually achieve a deeper level of comprehension cannot, however, be determined with certainty from these results. An alternative explanation might be that the observed differences did not arise during processing of the text, but rather during the recall phase. One would then have to speak of a retrieval effect where low-interest subjects were also capable of answering the deeper comprehension questions, but were simply not motivated to work hard on these recall tasks.

A second problem concerns the comprehension test. As in other studies, the comprehension test in Study I is not based upon a specific theory of text processing but rather uses intuitive criteria for determining different levels of comprehension.

Van Dijk and Kintsch's Theory of Text Comprehension. The text processing theory of van Dijk; and Kintsch (1983; see also Kintsch, 1986) was used to construct a theoretically based test of comprehension, because this theory differentiates between various text representations that can also be interpreted as different levels of comprehension. Van Dijk and Kintsch distinguish between the cognitive representation of a text and the representation of the "situation" that the text describes ("situation model"). Knowledge contained in the situation model is not dependent on the text 
and can also be derived from other sources (e.g., learning by doing). The situation model is distinguished from two forms of text-bound representation-the verbatim and the propositional representations, which together form the "text basis." The propositional text basis consists of both a microstructure, which contains the meaning of the text, and a macrostructure, which represents the "gist" of the text. The verbatim text representation is even more closely bound to the text than the propositional and contains the representation of the text's superficial structure. An example of a purely verbatim representation would be a person who memorizes a sentence in a foreign language without knowing its meaning.

According to Kintsch (1986) and Perrig and Kintsch (1985), a propositional text representation is adequate for enabling a subject to repeat a text. Learning, in the sense of applying what has been read to new situations (e.g., verification of sentences in a recognition test), can only take place, however, when a situation model has been developed. In order to investigate the strength of the individual components of text representation, Perrig and Kintsch (1985) and Schmalhofer and Glavanov (1986) used recognition tests in which the subjects were asked to verify various types of sentences.

Generally, the reader of a certain text will always construct verbatim, propositional, and situational representations. The extent of each type of representation can vary immensely, however (Perrig \& Kintsch, 1985; Schmalhofer \& Glavanov, 1986). While reading, the three types of representation are constructed simultaneously and influence one another in a reciprocal fashion. Nevertheless, the processes involved can be distinguished from one another and are stored separately in memory (Kintsch, 1986).

Elaborations also play an important role in the model of van Dijk and Kintsch. In principle, they can be found on all three levels of text representation. Elaborations contribute to the strength and duration of the memory trace formed by the three types of representation (Kintsch, 1979). A large number of elaborations, such as mental images, associations with personal experience, and connections with prior knowledge, probably facilitate the construction of the situation model. Theoretically, one would expect to find a clear correlation between the number of elaborations and the extent of the situational text representation.

Based on this model then, it was hypothesized that high-interest subjects would build propositional and situational text representations to a 
greater extent than would other students. Low-interest subjects, on the other hand, were expected to acquire a mainly verbatim comprehension of the text.

Measurement of Text Comprehension in Study II. A recognition test was constructed based on techniques developed by Schmalhofer and Glavanov (1986) and Perrig and Kintsch (1985). The test contained 30 sentences, which were given to subjects in random order. Six of each of the following types of sentences were included in the test: original (Osentences), para-phrased ( $\mathrm{P}$-sentences), meaning-changed (M-sentences), and correctness-changed ( $\mathrm{C}$-sentences). $\mathrm{P}$-sentences were constructed by changing a few words. M-sentences contained correct and reasonable inferences from the text, which could be recognized as correct only on the basis of the situation model. C-sentences contradicted the corresponding original sentences and were false in terms of the situation model.

In each case, the subjects had to decide whether a sentence was presented verbatim in the original text. If the subject indicated that the sentence was not found in the text, he or she was asked to indicate whether the sentence was true or false. Based on the subject's judgment, scores for the extent of the verbatim (VERB), propositional (PROP), and situational (SIT) representations of the text were determined. The strength of individual text representations was calculated by means of $d^{\prime}$-values ${ }^{3}$ (cf. Egan, 1975).

The $d^{\prime}$-value is a measure of the discriminability of two response distributions. The strength of the verbatim representation is determined by the difference between the number of "yes" answers for the Osentences ("hit rate") and the number of "yes" answers for the P-sentences ("false alarm rate"). Similarly, the strength of the propositional representation is determined by the difference between the "yes" answers for the $\mathrm{P}$-sentences and the false alarm rate for the $\mathrm{M}$-sentences. Finally, the extent of the situational representation is determined by the difference between the "yes" answers for the M-sentences and the "yes" answers for the $\mathrm{C}$-sentences. Determination of these differences is reasonable because the sentence pairs $\mathrm{O}-\mathrm{P}, \mathrm{P}-\mathrm{M}$, and $\mathrm{M}-\mathrm{C}$ differ only by the contribution of one representational type (Schmalhofer \& Glavanov, 1986, p. 285). All three representational forms are involved in a "yes" answer to an

${ }^{3}$ The $d^{\prime}$-value, according to Egan (1975, p. 61), is the difference between the mean values of two distributions divided by their shared variance. Its application requires that the accumulated recognition values exhibit both a normal distribution and a homogeneous variance. Both conditions are met in the present study. 
O-sentence, only propositional and situational representations are involved in the case of $\mathrm{P}$-sentences, and $\mathrm{M}$-sentences involve only the situational representation. In the case of the $\mathrm{C}$-sentences, all three representational forms contribute to a negative response.

Results of Study II. Table 7.4 displays mean $d^{\prime}$-values for low- and high-interest subjects. A significant main effect was obtained for type of representation (repeated measures ANOVA, $p<.05$ ). More importantly, the expected interaction between interest and representation appeared to be significant $(p<.01)$. The pattern of results confirms the hypotheses. Low-interest subjects have a more pronounced verbatim and a less pronounced propositional and situational text representation than highinterest subjects. However, a significant difference was found only in the case of the verbatim representation (planned comparison, $p<.05$ ). The effect of interest on the propositional representation $(p<.10)$ failed to reach an acceptable level of significance.

Table 7.4

Strength of Components of Text Representation ( $d^{\prime}$-values) as a Function of Topic Interest (Study II)

\begin{tabular}{ccc}
\hline & \multicolumn{2}{c}{ Topic Interest } \\
Text & Low & High \\
$(\mathrm{n}=19)$ & $(\mathrm{n}=22)$ \\
\hline VEResentation & .58 & -.11 \\
PROP & -.12 & .37 \\
SIT & .56 & .72 \\
\hline
\end{tabular}

In each recognition task, subjects were asked to decide not only whether a sentence came from the text, but also (in the case of a negative response) whether the sentence were true or false. Analysis of this verification task can yield additional insight into the type of text representation preferred by high- and low-interest subjects. Specifically, it should be indicative of the strength of the situational representation. Two ANOVAs were performed to examine the effects of interest on the verification of correct sentences $\left(\mathrm{O}_{-}, \mathrm{P}-\right.$, and $\mathrm{M}$-sentences) and incorrect 
sentences (C-sentences). The results show that interest exerted an influence on the verification of correct sentences $(p<.05)$, but not incorrect ones. Low-interest subjects were more likely than high-interest subjects to judge correct sentences to be false. A planned comparison revealed that the main effect for interest was significant only for $\mathrm{P}$ sentences $(p<.01)$. Low-interest subjects rejected, on the average, $21 \%$ of all $\mathrm{P}$-sentences as being true, whereas high-interest subjects did so only for $.08 \%$ of all P-sentences.

The results of Study II show that subjects who displayed a higher level of topic interest exhibited a less pronounced verbatim representation than low-interest subjects. Results regarding the propositional or meaning representation revealed only a nonsignificant trend in favor of highly interested students. No differences between situational representations of low- and high-interest subjects were observed. This result may indicate a lack of validity for the recognition test. The construction of meaningchanged sentences, which are crucial for calculating scores for the situational representation, is somewhat problematic. Although the whole test is based on a well-elaborated theory, there are no straightforward guidelines for constructing meaning-changed sentences. An analysis of the frequency of "yes" answers to all types of sentences shows that there were almost no differences between $\mathrm{M}$ - and $\mathrm{P}$-sentences. This indicates that $\mathrm{M}-$ sentences may not have been "difficult" enough.

In support of the hypothesis that interest affects the situational representation of text, it was found that low-interest subjects rejected significantly more correct sentences in the additional verification task than did high-interest subjects.

Interest, Intelligence, and Prior Knowledge

Measurement of Control Variables. In both studies, the measurement of the various components of intelligence that could be important for text comprehension was conducted by means of several sub-tests from the IQ test by Jäger and Althoff (1983). The sub-tests used were intended to yield a score for general intelligence as well as scores for verbal intelligence and short-term memory (STM) capacity. Subjects' prior knowledge of the texts' topics was measured using 5 open-ended questions on the text content.

Results of Study $I$. The first step in the analysis consisted of comparing the mean values of the control variables for high- and low-interest 
subjects. ${ }^{4}$ No significant differences were obtained. The mean values for the factors of general intelligence, verbal intelligence, STM capacity, and prior knowledge were nearly equal for high- and low-interest subjects. Thus, one must conclude that the differences in comprehension between the high- and low-interest groups were not attributable to these factors. This result is especially significant, as previous studies have found such factors to be of central importance in the learning of text material (e.g., Fincher-Kiefer, Post, Greene, \& Voss, 1988; Perfetti, 1983; Recht \& Leslie, 1988).

Contrary to expectations, prior knowledge and STM capacity did not correlate with comprehension. The indicators of verbal and general intelligence were correlated significantly only with the simple questions. ${ }^{5}$

In order to examine whether interest and intelligence show independent effects in the subsample analyzed here, partial correlation coefficients were computed. The results show that controlling for verbal and general intelligence did not reduce the correlations between interest and comprehension. Thus, the effects of interest and intelligence are independent of one another.

Results of Study II. Examination of the control variables in Study II revealed different results from Study I. Prior knowledge was found to be significantly correlated with interest $(r=.42, \mathrm{p}<.05)^{6}$ but had no influence on the indicators of comprehension. No significant differences were found between high- and low-interest subjects in terms of intelligence. However, the level of general intelligence tended to affect text comprehension. High intelligence was associated with less pronounced propositional and more pronounced situational representations. No effect of intelligence on verbatim representation was obtained. It seems that the relation between intelligence and representation is quite different from the relation between interest and representation.

There also were no significant relations between verbal intelligence, short-term memory, and comprehension, but similar trends for general intelligence did emerge.

\footnotetext{
${ }^{4}$ It should be noted that not all subjects in both samples took part in the data collection for the control variables. This is due to the fact that participation in the seminars in which the studies were conducted fluctuated widely.

5 A more detailed description and interpretation of these results is to be found in Schiefele (1990a).

${ }^{6}$ If not otherwise indicated, two-tailed tests of significance were carried out.
} 
Next, in order to examine whether interest, prior knowledge, and general intelligence showed independent effects on text representation like those in Study I, partial correlation coefficients were analyzed. The results are summarized in Table 7.5.

Table 7.5

Zero-Order and Partial Correlations for the Relation between Interest and Components of Text Representation (Study II)

\begin{tabular}{|c|c|c|c|c|}
\hline Sample & Control Variable & $I N T-V E R B$ & $I N T-P R O P$ & $I N T-S I T$ \\
\hline $\mathrm{TS}(n=41)$ & - & $-.50 * *$ & $.34 *$ & .08 \\
\hline $\begin{array}{l}\text { SS1 }(n=33) \\
\text { SS1 }(n=33)\end{array}$ & Prior knowledge & $\begin{array}{l}-.46 * * \\
-.57 * * *\end{array}$ & $\begin{array}{l}.33^{a} \\
.36^{*}\end{array}$ & $\begin{array}{l}.08 \\
.12\end{array}$ \\
\hline $\begin{array}{l}\mathrm{SS} 2(n=32) \\
\mathrm{SS} 2(n=32)\end{array}$ & Intelligence & $\begin{array}{l}-.49 * * \\
-.51 * *\end{array}$ & $\begin{array}{l}.38^{*} \\
.51^{* * *}\end{array}$ & $\begin{array}{l}.08 \\
.02\end{array}$ \\
\hline
\end{tabular}

${ }^{*} p<.05 ;{ }^{* *} p<.01 ;{ }^{* * *} p<.001 ;{ }^{\mathrm{a}} p=.061$.

Note: INT: Interest; TS: Total sample; SS1: Subsample 1 (all subjects who took part in the prior knowledge test); SS2: Subsample 2 (all subjects who took part in the intelligence test). SS1 and SS2 have 24 subjects in common.

The analysis of partial correlations revealed that controlling for prior knowledge and intelligence did not reduce the correlation between interest and the representational components. Note particularly that, when controlling for intelligence, the correlation between interest and PROP rises from .38 to .51 . This is presumably the result of the highly negative correlation between intelligence and PROP.

The effects of prior knowledge and intelligence in both studies were relatively independent of the interest effect. The small influence of prior knowledge on comprehension was probably due to the fact that students had very little knowledge of the topics. 
Interest and Mediating Processes

\section{Measurement of Process Variables}

Because the variables described here are all related to reading processes, they may serve to explain effects of interest. All of these variables were measured retrospectively, immediately following the reading of text. As depicted in Fig. 7.1, two groups of variables were distinguished: affective and cognitive processes (text processing). Activation and flow were examined as affective variables, and elaborations and learning techniques were examined as cognitive variables.

Activation. Level of activation was estimated using the "ActivationDeactivation Adjective Check List" (AD-ACL), developed by Thayer $(1985,1986)$. This scale allows the measurement of two independent bipolar activation dimensions: dimension A or "energetic arousal" (e.g., "energetic" vs. "sleepy"), and dimension B or "tense arousal" (e.g., "nervous" vs. "relaxed"). Only activation dimension A has been included in the present studies because it is closely related to motivational processes.

Flow. Using the concepts and methodology of Csikszentmihalyi (1975) and Massimini and Carli (1988), a questionnaire containing eight items for measuring the various components of flow was developed (e.g., "I had the impression that time went slowly while I was reading," "I was completely caught up in what I was reading"). Although the measure of flow was designed to tap a holistic state of mind covering different components, it seemed primarily to assess the experience of deep concentration. Because concentration is a central feature of flow, it becomes evident that flow is not a purely affective state.

Elaborations. A retrospective measure was employed to yield insight into elaborative processes. Subjects were asked to estimate to what extent the following four types of elaborations occurred: personal experience, content-related images, personal content-related thoughts or ideas, and paraphrasing the text in one's own words.

Underlinings and Margin Notes. Subjects were allowed to underline passages in the text and to make notes in the margins. Both methods can serve to assist remembering or comprehension of text passages (Anderson \& Armbruster, 1984; Wade \& Trathen, 1989).

\section{Results of Studies I and II}

In both Study I and Study II, significant correlations were found among interest and activation, flow, and elaboration (see Table 7.6 for the 
results from Study II). Relations between interest and underlining and note-taking turned out to be considerably weaker (see Table 7.6).

Inspection of the (5) individual flow items that were significantly related to level of interest indicated that time went by much faster for high-interest subjects, that they were much more caught up in the text, and that they experienced greater alertness and deeper concentration than lowinterest subjects.

A look at the relations between individual items from the elaboration scale and interest showed that high-interest subjects more frequently reported the occurrence of mental images and personal thoughts about the text content. In addition, they tried harder to paraphrase the text.

Table 7.6

Zero-Order Correlations between Interest, Verbatim, and Propositional Text Representations, and Process Variables (Study II)

\begin{tabular}{lccccc}
\hline & Activation & Flow & Elaboration & Notes & Underlining \\
\hline INT & $.57^{* * *}$ & $.56^{* * *}$ & $.60^{* * *}$ & $.28^{\mathrm{a}}$ & $.28^{\mathrm{a}}$ \\
VERB & $-.27^{\mathrm{a}}$ & -.25 & $-.48^{* *}$ & -.22 & -.05 \\
PROP & .20 & $.27^{\mathrm{a}}$ & $.27^{\mathrm{a}}$ & $.60^{* * *}$ & .12 \\
\hline
\end{tabular}

${ }^{*} p<.05 ;{ }^{* *} p<.01 ;{ }^{* * *} p<.001 ;{ }^{\mathrm{a}} p=.061$.

Note: $n=41$; INT: Interest.

What can be said about the mediating role of the process variables studied? The results of Study I suggest a negative answer. Entering the process variables into a regression equation together with interest did not reduce the regression coefficient of interest for predicting complex questions of knowledge and questions of deeper understanding.

A different picture emerged in Study II. First, from the correlation values depicted in Table 7.6, it can be seen that cognitive process variables exhibited stronger relations to measures of text representation than did affective process variables. Not surprisingly, the amount of elaboration was negatively correlated with the strength of the verbatim representation. 
An unexpectedly strong relation appears to exist between note-taking behavior and the representation of meaning.

Two separate multiple regressions were run to test mediational hypotheses. First, it was found that entering activation, flow, and elaboration into the regression equation for predicting VERB reduced the standardized regression coefficient of interest from -.50 to -.29 , the latter value now being only marginally significant $(F-$ Test, $p<.077)$. Second, the inclusion of flow, elaboration, and notes in the regression equation for predicting PROP reduced the regression coefficient of interest from .34 to a nonsignificant value of .17. These results suggest that interest, in fact, exerts substantial influence on the processes that contribute to the representation of the meaning of a text.

\section{CONCLUSION}

At the outset of this chapter we took a look at the history of educational research. We found that assumptions about the relation between interest and learning were at the core of educational theories developed by scholars such as Herbart and Dewey, who both hypothesized that interestbased learning processes greatly differ qualitatively from effort-based, externally motivated learning processes. A review of more recent studies on the relation between interest and text learning revealed that most researchers have neglected to investigate the qualitative features of interest-based learning and have stressed purely quantitative outcomes.

The empirical studies reported in this chapter were designed to overcome the failure of prior research to analyze the relation between interest and comprehension more systematically. Study I confirmed that the effect of interest on comprehension is more pronounced at deeper levels of understanding. In keeping with Dewey's theory, low- and highinterest students did not differ significantly with regard to knowledge acquired by rote learning. Study II supported the results from Study I in showing that high-interest subjects displayed less verbatim and more meaning-oriented (propositional) text processing than low-interest subjects. In addition, results for control variables confirmed the independent effect of interest on text processing.

In order to gain a more detailed impression of the difference between interest-oriented and noninterest-oriented text processing styles, both studies included retrospective measures of several process variables. Analysis of these variables showed that a high level of topic interest 
contributes to an increased level of activation and the experience of flow. In addition, high interest subjects engaged in more pronounced elaborative processing and made more use of learning techniques. The exploration of mediating effects in Study II showed that the process variables could mediate at least part of the interest effect on comprehension. Additionally, the results suggested that cognitive process variables are more important than affective variables for mediating the effect of interest.

One problem with these results is that the measurement of process variables was almost exclusively (with the exception of notes and underlinings) based on verbal self-reports. The difficulties associated with reports of this nature are well known (Ericsson \& Simon, 1980; Nisbett \& Wilson, 1977 ). Future studies might supplement the measurement of process variables with other methods, such as think-aloud protocols (cf. Renninger, 1991) and on-line ratings.

As so often happens with research, there are more questions at the end than at the beginning. The following questions might serve as guidelines for future research.

1. Has prior knowledge been adequately measured? The tests of prior knowledge in both of the present studies were related only to knowledge explicitly contained in the texts. A possible refinement would be to include knowledge that, though not explicitly stated in the text itself, does pertain to the text's general topical domain (e.g., psychological knowledge).

2. How does the length of individual reading time influence the interest effect? At first glance, it seems reasonable that greater interest would be associated with slower reading, since greater interest would result in a more intensive processing of the text. On the other hand, it is conceivable that the interested reader simply "gobbles up" a text, finishing more quickly than an uninterested reader, who has to fight just to keep on reading (cf. Shirey \& Reynolds, 1988; Hidi, 1990).

3. What influence do the instructions given before reading have on the relation between interest and comprehension? A very plausible assumption is that the interest effect is dependent on particular reading instructions. The announcement of a recall or comprehension test could, under certain conditions, hide the interest effect.

4. Are the results of the present studies also applicable to text-based, situational forms of interest? It would be interesting to apply the approach presented here to text-induced interest. This would allow 
a comparison of the effects of individual and situational interest, and could thus help us to evaluate their respective merits.

5. How do the cognitive characteristics of the learner interact with interest? This is a problem of considerable significance because the results of the present studies imply that cognitive factors have effects on comprehension that are different from those of interest. A related and even more interesting question might be whether a high level of interest can compensate for deficits in cognitive functioning.

\section{ACKNOWLEDGMENTS}

Parts of the research reported in this chapter were supported by a grant from the Deutsche Forschungsgemeinschaft to Andreas Krapp and the author (Kr 716/4-1).

Preparation of the paper was facilitated by a scholarship awarded to the author by the Deutsche Forschungsgemeinschaft. Special thanks go to Steve Adams, who translated large parts of the original manuscript.

\section{REFERENCES}

Anderson, R. C. (1982). Allocation of attention during reading. In A. Flammer \& W. Kintsch (Eds.), Discourse processing (pp. 292-313). Amsterdam: North-Holland.

Anderson, R. C., Mason, J., \& Shirey, L. L. (1984). The reading group: An experimental investigation of a labyrinth. Reading Research Quarterly, 20, 638.

Anderson, R. C., Shirey, L. L., Wilson, P. T., \& Fielding, L. G. (1987) Interestingness of children's reading material. In R. E. Snow \& M. J. Farr (Eds.), Aptitude, learning, and instruction. Vol. 3: Conative and affective process analyses (pp. 287-299). Hillsdale, NJ: Lawrence Erlbaum Associates.

Anderson, T. H. \& Armbruster, B. B. (1984). Studying. In P. D. Pearson (Ed.), Handbook of reading research (pp. 657-679). New York: Longman.

Asher, S. R. (1980). Topic interest and children's reading comprehension. In R. J. Spiro, B. C. Bruce, \& W. F. Brewer (Eds.), Theoretical issues in reading comprehension (pp. 525-534). Hillsdale, NJ: Lawrence Erlbaum Associates.

Baldwin, R. S., Peleg-Bruckner, Z., \& McClintock, A. H. (1985). Effects of topic interest and prior knowledge on reading comprehension. Reading Research Quarterly, 20, 497-504.

Ballstaedt, S.-P. \& Mandl, H. (1987). Influencing the degree of reading comprehension. In E. van der Meer \& J. Hoffmann (Eds.), Knowledge aided information processing (pp. 119-139). Amsterdam: Elsevier. 
Belloni, L. F. \& Jongsma, E. A. (1978). The effects of interest on reading comprehension of low-achieving students. Journal of Reading, 22, 106-109.

Benware, C. A. \& Deci, E. L. (1984). Quality of learning with an active versus passive motivational set. American Educational Research Journal, 21, 755765.

Bernstein, M. R. (1955). Relationship between interest and reading comprehension. Journal of Educational Research, 49, 283-288.

Bloom, B. S. (Ed.) (1985). Developing talent in young people. New York: Ballentine.

Bower, G. H. \& Cohen, P. R. (1982). Emotional influences in memory and thinking: Data and theory. In M. S. Clark \& S. T. Fiske (Eds.), Affect and cognition (pp. 291-331). Hillsdale, NJ: Lawrence Erlbaum Associates.

Cattell, R. B. (1936). The measurement of interest. Character \& Personality, 4, $147-169$.

Cecil, N. L. (1984). Impact of interest on the literal comprehension of beginning readers-a West Indian study. The Reading Teacher, 37, 750-753.

Csikszentmihalyi, M. (1975). Beyond boredom and anxiety. San Francisco: Jossey-Bass.

Csikszentmihalyi, M. (1988). Motivation and creativity: Towards a synthesis of structural and energistic approaches to cognition. New Ideas in Psychology, $6,159-176$.

Csikszentmihalyi, M. (1990). Flow-The psychology of optimal experience. New York: Harper \& Row.

Csikszentmihalyi, M., \& Csikszentmihalyi, I. S. (Eds.) (1988). Optimal experience: Psychological studies of flow in consciousness. Cambridge, MA: Cambridge University Press.

Csikszentmihalyi, M., \& Larson, R. (1987). Validity and reliability of the experience-sampling method. The Journal of Nervous and Mental Disease, $175,526-536$

Csikszentmihalyi, M., \& LeFevre, J. (1989). Optimal experience in work and leisure. Journal of Personality and Social Personality, 56, 815-822.

Deci, E. L., \& Ryan, R. M. (1985). Intrinsic motivation and self-determination in human behavior. New York: Plenum Press.

Dewey, J. (1913). Interest and effort in education. Boston: Riverside Press.

Dweck, C. S. (1986). Motivational processes affecting learning. American Psychologist, 41, 1040-1048.

Dweck, C. S., \& Leggett, E. L. (1988). A social-cognitive approach to motivation and personality. Psychological Review, 95, 256-273.

Egan, J. P. (1975). Signal detection theory and ROC analysis. New York: Academic Press.

Entin, E. B. \& Klare, G. R. (1985). Relationships of measures of interest, prior knowledge, and readability to comprehension of expository passages. Advances in Reading/Language Research, 3, 9-38.

Entwistle, N. (1988). Motivational factors in students' approaches to learning. In R. R. Schmeck (Ed.), Learning strategies and learning styles (pp. 21-52). New York: Plenum Press.

Entwistle, N. J., \& Ramsden, P. (1983). Understanding student learning. London: Croom Helm. 
Ericsson, K. A., \& Simon, H. A. (1980). Verbal reports as data. Psychological Review, 87, 215-251.

Eysenck, M. W. (1982). Attention and arousal. Berlin: Springer.

Fincher-Kiefer, R., Post, T. A., Greene, T. R., \& Voss, J. F. (1988). On the role of prior knowledge and task demands in the processing of text. Journal of Memory and Language, 27, 416-428.

Fransson, A. (1977). On qualitative differences in learning: IV-Effects of intrinsic motivation and extrinsic test anxiety on process and outcome. British Journal of Educational Psychology, 47, 244-257.

Groff, P. J. (1962). Children's attitudes toward reading and their critical reading abilities in four content-type materials. Journal of Educational Research, 55, 313-317.

Grolnick, W. S., \& Ryan, R. M. (1987). Autonomy in children's learning: An experimental and individual difference investigation. Journal of Personality and Social Psychology, 52, 890-898.

Guttmann, G. (1982). Lehrbuch der Neuropsychologie. Bern: Huber.

Hare, V. C., \& Devine, D. A. (1983). Topical knowledge and topical interest predictors of listening comprehension. Journal of Educational Research, 76, $157-160$.

Harter, S. (1981). A new self-report scale of intrinsic versus extrinsic orientation in the classroom: Motivational and informational components. Developmental Psychology, 17, 300-312.

Herbart, J. F. (1806). Allgemeine Pädagogik, aus dem Zweck der Erziehung abgeleitet. In J. F. Herbart, Pädagogische Schriften (1965, Vol. 2, pp. 9155). Düsseldorf: Küpper.

Herbart, J. F. (1841). Umriß pädagogischer Vorlesungen. In J. F. Herbart, Pädagogische Schriften (1965, Vol. 3, pp. 157-300). Düsseldorf: Küpper.

Hidi, S. (1990). Interest and its contribution as a mental resource for learning. Review of Educational Research, 60, 549-571.

Hidi, S. \& Baird, W. (1986). Interestingness-A neglected variable in discourse processing. Cognitive Science, 10, 179-194.

Hidi, S. \& Baird, W. (1988). Strategies for increasing text-based interest and students' recall of expository texts. Reading Research Quarterly, 23, 465483.

Hidi, S. \& McLaren, J. (1988, April). The effect of topic and theme interestingness on children's school performance. Paper presented at the annual meeting of the American Educational Research Association, New Orleans.

Isen, A. M., Daubman, K. A., \& Gorgoglione, J. M. (1987). The influence of positive affect on cognitive organization: Implications for education. In R. E. Snow \& M. J. Farr (Eds.), Aptitude, learning, and instruction. Vol. 3: Conative and affective process analyses (pp. 143-164). Hillsdale, NJ: Lawrence Erlbaum Associates.

Jäger, A. O., \& Althoff, K. (1983). Der Wilde-Intelligenz-Test (WIT). Göttingen: Hogrefe.

Johnson, J. C., \& Jacobson, M. D. (1968). Some attitudinal and comprehension factors operating in the middle grades. Educational and Psychological Measurement, 28, 825-832.

Kerschensteiner, G. (1922). Theorie der Bildung. Leipzig: Teubner. 
Kintsch, W. (1979). Levels of processing language material: Discussion of the papers by Lachman and Lachman and Perfetti. In L. S. Cermak \& F. I. M. Craik (Eds.), Levels of processing in human memory (pp. 211-222). Hillsdale, NJ: Lawrence Erlbaum Associates.

Kintsch, W. (1986). Learning from text. Cognition and Instruction, 3, 87-108.

Klein, H. A. (1979). What effect does non-sexist content have on the reading of boys and girls. Reading Improvement, 16, 134-138.

Krapp, A. (1989, September). Interest, learning, and achievement. Paper presented at the 3rd meeting of the European Association for Research in Learning and Instruction, Madrid.

Krapp, A. \& Fink, B. (1987, April). Development of interests as change in individual person-object relationships. Paper presented at the biennial meeting of the Society for Research in Child Development, Baltimore.

Larson, R. (1988). Flow and writing. In M. Csikszentmihalyi \& I. S. Csikszentmihalyi (Eds.), Optimal experience: Psychological studies of flow in consciousness (pp. 150-171). Cambridge, MA: Cambridge University Press.

Lepper, M. R. (1988). Motivational considerations in the study of instruction. Cognition and Instruction, 5, 289-309.

Mandl, H. \& Huber, G. L. (Eds.) (1983). Emotion und Kognition. München: Urban \& Schwarzenberg.

Massimini, F. \& Carli, M. (1988). The systematic assessment of flow in daily experience. In M. Csikszentmihalyi \& I. S. Csikszentmihalyi (Eds.), Optimal experience: Psychological studies of flow in consciousness (pp. 266-287). Cambridge, MA: Cambridge University Press.

Nicholls, J. G. (1984). Achievement motivation: Conceptions of ability, subjective experience, task choice, and performance. Psychological Review, $91,328-345$.

Nisbett, R. E., \& Wilson, T. D. (1977). Telling more than we can know: Verbal reports on mental processes. Psychological Review, 84, 231-259.

Nolen, S. B. (1988). Reasons for studying: Motivational orientations and study strategies. Cognition and Instruction, 5, 269-287.

Osako, G. N. \& Anders, P. L. (1983). The effect of reading interest on comprehension of expository materials with controls for prior knowledge. In J. A. Niles \& L. A. Harris (Eds.), Searches for meaning in reading/language arts processing instruction (pp. 56-60). Rochester, NY: National Reading Conference.

Pekrun, R. (1988). Emotion, Motivation und Persönlichkeit. München/Weinheim: Psychologie Verlags Union.

Perfetti, C. A. (1983). Individual differences in verbal processes. In R. F. Dillon \& R. R. Schmeck (Eds.), Individual differences in cognition (Vol. 1, pp. 65-104). New York: Academic Press.

Perrig, W., \& Kintsch, W. (1985). Propositional and situational representations of text. Journal of Memory and Language, 24, 503-518.

Prenzel, M. (1988). Die Wirkungsweise von Interesse. Opladen: Westdeutscher Verlag.

Prenzel, M., Krapp, A., \& Schiefele, H. (1986). Grundzüge einer pädagogischen Interessentheorie. Zeitschrift für Pädagogik, 32, 163-173.

Rathunde, K. (1989). The context of optimal experience: An exploratory model of the family. New Ideas in Psychology, 2, 91-97. 
Recht, D. R. \& Leslie, L. (1988). Effect of prior knowledge on good and poor readers' memory of text. Journal of Educational Psychology, 80, 16-20.

Renninger, K. A. (1988, April). Effects of interest and noninterest on student performance with tasks of mathematical word problems and reading comprehension. Paper presented at the annual meeting of the American Educational Research Association, New Orleans.

Renninger, K. A. (1990). Children's play interests, representation, and activity. In R. Fivush \& J. Hudson (Eds.), Knowing and remembering in young children (pp. 127-165). Cambridge, MA: Cambridge University Press.

Renninger, K. A. (1991, April). Influences of interest and task difficulty on students' strategies for reading and recall. Paper presented as part of the symposium, Effects of Interest on Strategies and Learning from Text. American Educational Research Association, Chicago, IL.

Renninger, K. A., \& Wozniak, R. H. (1985). Effect of interest on attentional shift, recognition, and recall in young children. Developmental Psychology, $21,624-632$.

Ryan, R. M. (1982). Control and information in the intrapersonal sphere: An extension of cognitive evaluation theory. Journal of Personality and Social Psychology, 43, 450-461.

Schiefele, H., Hausser, K., \& Schneider, G. (1979). "Interesse" als Ziel und Weg der Erziehung. Überlegungen zu einem vernachläßigten pädagogischen Konzept. Zeitschrift für Pädagogik, 25, 1-20.

Schiefele, H., Krapp, A., Prenzel, M., Heiland, A., \& Kasten, H. (1983, July/August). Principles of an educational theory of interest. Paper presented at the 7 th biennial meeting of the International Society for the Study of Behavioral Development, Munich.

Schiefele, U. (1987). The importance of motivational factors for the acquisition and representation of knowledge. In P. R. J. Simons \& G. Beukhof (Eds.), Regulation of learning (pp. 47-69). Den Haag: SVO Selecta.

Schiefele, U. (1988). Motivationale Bedingungen des Textverstehens. Zeitschrift für Pädagogik, 34, 687-708.

Schiefele, U. (1990a). The influence of topic interest, prior knowledge, and cognitive capabilities on text comprehension. In J. M. Pieters, K. Breuer, \& P. R. J. Simons (Eds.), Learning environments (pp. 323-338). Heidelberg: Springer.

Schiefele, U. (1990b). Thematisches Interesse, Variablen des Leseprozesses und Textverstehen. Zeitschrift für Experimentelle und Angewandte Psychologie, 37, 304-332.

Schiefele, U. (in press a). Interesse und Textrepräsentation-Zur Auswirkung des thematischen Interesses auf unterschiedliche Komponenten der Textrepräsentation unter Berücksichtigung kognitiver und motivationaler Kontrollvariablen. Zeitschrift für Pädagogische Psychologie.

Schiefele, U. (in press b). Interest, learning, and motivation. Educational Psychologist.

Schiefele, U. \& Krapp, A. (1988, April). The impact of interest on qualitative and structural indicators of knowledge. Paper presented at the annual meeting of the American Educational Research Association, New Orleans.

Schiefele, U. \& Winteler, A. (1988). Interesse-Lernen-Leistung. Eine Übersicht über theoretische Konzepte, Erfassungsmethoden und Ergebnisse 
der Forschung (Gelbe Reihe, Arbeiten zur Empirischen Pädagogik und Pädagogischen Psychologie, Nr. 14). München: Universität der Bundeswehr.

Schiefele, U., Winteler, A., \& Krapp, A. (1988). Studieninteresse und fachbezogene Wissensstruktur. Psychologie in Erziehung und Unterricht, 35, 106-118.

Schmalhofer, F., \& Glavanov, D. (1986). Three components of understanding a programmer's manual: Verbatim, propositional, and situational representations. Journal of Memory and Language, 25, 279-294.

Shirey, L. L., \& Reynolds, R. E. (1988). Effect of interest on attention and learning. Journal of Educational Psychology, 80, 159-166.

Stevens, K. (1979). The effect of topic interest on the reading comprehension of higher ability students. Journal of Educational Research, 73, 365-368.

Thayer, R. E. (1985). Activation (arousal): The shift from a single to a multdimensional perspective. Biological Bases of Personality and Behavior, $1,115-127$.

Thayer, R. E. (1986). Activation-deactivation adjective check list: Current overview and structural analysis. Psychological Reports, 58, 606-614.

Thayer, R. E., \& Cox, S. J. (1968). Activation, anxiety, and verbal learning. Journal of Experimental Psychology, 78, 524-526.

Thorndike, E. L. (1935a). Adult interests. New York: MacMillan.

Thorndike, E. L. (1935b). The psychology of wants, interests and attitudes. New York: Appleton-Century.

van Dijk, T., \& Kintsch, W. (1983). Strategies of discourse comprehension. Orlando: Academic Press.

Wade, S. E., \& Trathen, W. (1989). Effect of self-selected study methods on learning. Journal of Educational Psychology, 81, 40-47.

Witty, P. A., \& Kopel, D. (1936). Motivating remedial reading: The interest factor. Educational Administration and Supervision, 22, 1-19. 